\title{
The influence of sociodemographic variables in the triggering of emotional symptoms after an air disaster
}

\author{
A influência das variáveis sociodemográficas no \\ desencadeamento de sintomas emocionais, \\ após um desastre aéreo
}

Gabriela LENHARDT ${ }^{1}$ ID 0000-0003-3689-642X

llana ANDRETTA 1 (ID) 0000-0002-5537-5120

\begin{abstract}
The study aimed to identify the predictive relationship of sociodemographic variables and emotional symptoms related to post-traumatic stress disorder, depression, anxiety, and stress. A sample of 194 people who experienced an air disaster, average age of 32 years, participated in the survey. The instruments used were: Sociodemographic Data Questionnaire, Post-Traumatic Stress Disorder Checklist - Civilian Version, and Depression Anxiety and Stress Scale. A multiple regression analysis indicated that women participants were associated with post-traumatic stress disorder symptoms and those directly exposed to the disaster had higher odds ratios to develop post-traumatic stress disorder, depression, and stress symptoms. It is expected, with this information, to identify early the people who may be most vulnerable and contribute to the elaboration of intervention protocols.
\end{abstract}

Keywords: Anxiety; Depression; Post-traumatic stress disorder.

\section{Resumo}

O estudo objetivou identificar a relação preditiva das variáveis sociodemográficas e os sintomas emocionais relativos ao transtorno de estresse pós-traumático, depressão, ansiedade e estresse. Participaram da pesquisa 194 pessoas com média

\footnotetext{
$7 \nabla$

1 Universidade do Vale do Rio dos Sinos, Departamento de Psicologia, Programa de Pós-Graduação em Psicologia. Av. Unisinos, 950, Cristo Rei, 93022-750, São Leopoldo, RS, Brasil. Correspondence to: I. ANDRETTA. E-mail: <iandretta@unisinos.br>.

Article based on the master's thesis of G. LENHARDT, entitled "Estratégias de coping e sintomas emocionais, após um desastre aéreo". Universidade do Vale do Rio dos Sinos, 2019.

How to cite this article

Lenhardt, G., \& Andretta, I. (2021). The influence of sociodemographic variables in the triggering of emotional symptoms after an air disaster. Estudos de Psicologia (Campinas), 38, e190154. https://doi.org/10.1590/1982-0275202138e190154
} 
de idade de 32 anos e que vivenciara um desastre aéreo. Os instrumentos utilizados na avaliação foram: Questionário de Dados Sociodemográficos, Post-Traumatic Stress Disorder Checklist - Civilian Version e Depression Anxiety and Stress Scale. Uma análise de regressão múltipla indicou que as participantes mulheres tiveram associações com os sintomas do transtorno de estresse pós-traumático e que as pessoas expostas diretamente aos desastres apresentaram maiores chances de desenvolver sintomas de transtorno de estresse pós-traumático, depressão e estresse. Espera-se, com essas informações, identificar precocemente as pessoas que possam estar mais vulneráveis e contribuir para a elaboração de protocolos de intervenção.

Palavras-chave: Ansiedade; Depressão; Transtornos de estresse pós-traumáticos.

Disasters are considered sudden and catastrophic events that can cause an experience of collective trauma, impacting people's emotional health at different levels, regardless of their geographical location with what happened (Mao, Fung, Hu, \& Loke, 2018). Such implications are influenced by a number of factors, including media coverage, making a lot of people feel like they are participating only because they follow the repercussions, regardless of their geographical proximity to the event (van Der Velden, van Der Meulen, Lenferink, \& Yzermans, 2018).

Parallel to this, Chung, Easthope, Chung, and Clark-Carter (2001) classify six populations affected by these phenomena. The authors categorized these people into primary, secondary, tertiary, quaternary, quinary, and senary victims. According to these classifications, in this study the victims were separated in: Direct (primary, secondary, tertiary), consisting of the subjects who had maximum exposure, family members, close friends, and rescue workers who assisted in the tragedy, and the victims: Indirect (quaternary, quinary and senary), represented by distant friends, other workers, and members of community that witnessed the event (Catanesi et al., 2013).

In this scenario, a number of studies reveal that people exposed to a disaster tend to experience intense and degradable emotional, cognitive, and physical symptoms during the first 72 hours, considered compatible with the situation experienced (Laugharne, van Der Watt, \& Janca, 2011). In contrast, when these reactions become frequent, causing suffering and impairment in social functioning and other important areas of life, it can be characterized as a psychopathological disorder (American Psychiatric Association [APA], 2014; Reis \& Carvalho, 2016).

Regarding the psychopathological consequences caused by disasters, the literature points to a wide range of symptoms and mental illnesses (Cénat \& Derivois, 2014). However, previous studies have documented that the most commonly studied and manifested reaction has been anxiety (Hiany, Vieira, Gusmão, \& Barbosa, 2020). According to Barlow (2016), anxiety is a state of mood which is oriented towards the future, associated with the preparation for a negative situation, but which can be considered maladaptive, as this emotion becomes exaggerated, as well as the level of activation and duration are disproportionate to the stimulus. Disaster studies have found that the highest prevalence, in the anxiety disorder category, has been linked to Post-Traumatic Stress Disorder (PTSD) (Farooqui et al., 2017; North, 2016).

Post-Traumatic Stress Disorder is characterized by a reaction of intense fear, impotence, or horror when individuals experience, witness, or are confronted with one or more events that involve death, serious injury or threat to their own or other people's physical integrity. Symptoms involve traumatic reexperience, psychic hyperexcitability, avoidance, and emotional detachment (Hibberd, Elwood, \& Galovski, 2014). Considering the changes in terms of diagnosis to the fifth edition of the Diagnostic and Statistical Manual of Mental Disorders (DSM) propose that PTSD occurs both when the person experiences or witnesses the situation, as well as it can be developed by subjects who heard that a traumatic event occurred to a family member or close friend, or those who are frequently exposed to the aversive details of the event (APA, 2014; Walton et al.,

2 2017). Nevertheless, studies indicate that subjects with tendencies to develop this disorder have associations 
with other emotional symptoms (Emygdio et al., 2019). Depression is among the most prevalent comorbid psychopathologies (León-Amenero \& Huarcaya-Victoria, 2019).

Depression is characterized by sadness, loss of interest and pleasure, feelings of guilt and emptiness, disturbed sleep and/or appetite, difficulty concentrating, fatigue and loss of energy (Organização Pan-Americana da Saúde [OPAS], 2018). In addition to depression and post-traumatic stress disorder, it has been described that traumatic situations, too, can precipitate stress symptoms. The consequences caused by stress symptoms involve difficulty in relaxing, nervous excitement, agitation, irritability, impatience, among other signs.

It is noteworthy, however, that the emotional impacts caused by disasters are quite variable in individual terms, that is, not all individuals exposed develop PTSD, depression, anxiety, and stress symptoms (Kristensen, Weisæth, \& Heir, 2014). According to Bonanno, Brewin, Kaniasty, and Greca (2010), the occurrence and severity of psychological reactions are influenced by personal characteristics, which indicates that some subjects are more vulnerable than others.

Among the main variables identified as moderators of mental illnesses, the following stand out: women (León-Amenero \& Huarcaya-Victoria, 2019); younger people and older adults (Borba et al., 2017; North et al., 2015); lower educational levels (Arnberg, Michel, \& Lundin, 2015; Quadros et al., 2020); widowed, divorced, or single marital status (Preto et al., 2018; Santos, Alves, Goldbaum, Cesar, \& Gianini, 2019) and direct exposure to the disaster (Tsujiuchi et al., 2016).

In view of the above, it is considered relevant to identify individual vulnerability factors, since sociodemographic characteristics influence the triggering of emotional symptoms. Early detection of people who may be more susceptible is extremely important, so that the manifestation and chronification of emotional symptoms and other psychopathologies can be minimized (Farooqui et al., 2017). Thus, it is expected that these data will assist in the planning of interventions with populations affected by disasters and other emergencies, providing the subjects with better recovery during and after the trauma. In this sense, the present article aims to verify if the sociodemographic variables - sex, age, educational level, marital status, and relationship with the tragedy - are predictors of emotional symptoms related to post-traumatic stress disorder, anxiety, depression and stress. It is hypothesized by the literature review that victims directly have more symptoms and that emotional symptoms are influenced by the sociodemographic variables analyzed.

\section{Method}

This is a quantitative, transversal, and explanatory study (Sampieri, Collado, \& Lucio, 2013).

\section{Participants}

The research was carried out with 194 subjects who experienced the air accident involving the Associação Chapecoense de Futebol (Chapecoense Football Association) team. The tragedy occurred in November 2016, when the charter flight of an Avro RJ85, operated by LaMia (Flight 2933), carrying the team's delegation to the final match of a tournament, crashed in Colombia, killing 71 people, including players, staff, journalists, and guests. The participants of this study are family members - father, son, spouse, brother, nephew, uncle and coworker, close friend and distant friend, idol, fans, and members of the community that witnessed or learned about the tragedy. All people are over 18, selected by the non-probabilistic sampling criteria, snowball, accessed and invited via social networks. There were no exclusion criteria, after the entry of participants who met the exclusion criteria in the study. 


\section{Instruments}

Sociodemographic Data Questionnaire: consists of an instrument developed by the authors to collect sociodemographic information and to characterize the sample studied (sex, age, marital status, educational level, and relationship with the disaster).

Post-Traumatic Stress Disorder - Checklist - Civilian Version (PCL-C): the instrument was originally developed by Weathers, Litz, Herman, Huska, and Keane (1993) and its semantic equivalence for Portuguese was made by Berger, Mendlowicz, Souza, and Figueira (2004). It consists of a self-report instrument of the Likert type that assesses the intensity of post-traumatic stress disorder symptoms, according to the criteria established by the DSM-IV. The Cronbach's alpha coefficient obtained for the present study was 0.936. In this instrument, the participants answered 17 questions, indicating the intensity of the symptoms during the last month. The analysis of the PCL-C was performed by grouping according to the indications proposed by Berger et al. (2004), with the individual needing to present, besides criterion A, a clinically significant symptom of criterion B (reliving), three items of criterion C (avoidance) and two items of criterion D (excitability).

Depression Anxiety and Stress Scale (DASS-21): the scale was originally developed by Lovibond and Lovibond (1995), later adapted and validated in Brazil by Apóstolo, Mendes, and Azeredo (2006). This instrument is freely accessible and self-applicable, being used in the short version composed of 21 items. The scale consists of a set of three subscales containing seven Likert-type questions with four possible answers (0-3 points). Each subscale consists of seven questions that simultaneously assess emotional states: depression, anxiety, and stress, during the last week (Apóstolo et al., 2006). Cronbach's Alphas coefficients were: Depression 0.899 , anxiety 0.869 , and stress 0.896 . The intensities of the domains correspond to the following classifications - depression, the score ranges are: 0 to 13 (normal and mild), 14 to 20 (moderate), and 21 to 42 (severe and extremely severe). For the anxiety domain: 0 to 9 (normal and mild), 10 to 14 (moderate), and 15 to 42 (severe and extremely severe). Finally, the stress domain: 0 to 18 (normal and mild), 19 to 25 (moderate), and 26 to 42 (severe and extremely severe). For the analysis of the scale, the subjects were stratified into two categories of intensity: (0) those with normal, mild, and moderate symptoms; and (1) those with severe and extremely severe symptoms. For this study, specifically, the participants were grouped into two expressive categories: (0) those with normal, low, and moderate symptoms; and (1) those with severe and extremely severe symptoms.

\section{Procedures}

This research was submitted and approved by the Psychology Ethics Committee of the the Universidade do Vale do Rio dos Sinos (University of Vale do Rio dos Sinos), opinion n ${ }^{\circ}$ 2.762.254, Certificado de Apresentação para Apreciação Ética (CAAE, Presentation Certificate for Ethical Appreciation) protocol $n^{\circ} 88500218.3 .0000 .5344$. All ethical principles in research with human beings were respected, according to Resolution $n^{\circ} 466 / 2012$. of the Conselho Nacional de Saúde (National Health Council). For data collection, individual contact was made through social networks (Facebook and Instagram) with people who might have some kind of relationship with the tragedy. In this request, the objectives of the study were explained, as well as the anonymous nature and the voluntary nature of participation was ensured, giving them the right to quit the study at any time without any consequences. The subjects who agreed to participate signed the Informed Consent Form and completed the online instruments (questionnaire and scales), elaborated through the Google Docs tool. As individuals were invited, they were requested to indicate other people who could collaborate with this study. Data were collected from September to 4 December 2018. 


\section{Data Analysis}

For data analysis, all questionnaires were initially exported from Google Docs to an Excel spreadsheet. Subsequently, the bank was exported to the Stata Statistical Software Release software (version 13.0), in which all analyzes were performed. The numerical variables were described by mean and Standard Deviation (SD) and the categorical variables by means of absolute and relative frequencies. Initially, descriptive analyzes were performed on the data obtained in the Sociodemographic Data Questionnaire to characterize the sample. Then, the prevalence of emotional symptoms were identified using the PCL-C and DASS-21 instruments.

In the bivariate analysis, there was an association between the sociodemographic variables and the levels of symptoms assessed, using Pearson's Chi-Square test. In addition, analyzes were carried out to identify the effect size of the analyzes, using Cramer's $\vee$ coefficient.

In the multivariate analysis, to adjust the predictive relationship between sociodemographic characteristics and emotional symptoms corresponding to PTSD, depression, anxiety, and stress, an adjusted logistic regression was developed. The analysis was adjusted for all independent variables (sociodemographic) in the same model at the same time. All dependent variables were treated as categorical variables. The estimated effect measure was the Odds Ratio (OR) with their respective 95\% Confidence Intervals (95\% CI). Associations with $p<0.05$ were considered statistically significant.

\section{Results}

The sample of the present study had 194 people, most of whom were single, with incomplete and complete higher education, and with a mean age of 32.1 years (SD: 11.4). According to the stratification of the sample, most participants correspond to indirect victims (distant friend, idol, fans, and members of the community that witnessed the tragedy), did not have PTSD symptoms. Regarding the intensity of depression, anxiety, and stress symptoms, the data revealed that most participants had symptoms within the normal score (Table 1).

Table 1

Sample description and prevalence of emotional symptoms $(N=194)$

\begin{tabular}{lcc} 
& & 1 of 2 \\
\hline Sociodemographic variables & $N$ & $\%$ \\
\hline Sex & & \\
Men & 101 & 47.4 \\
Women & & 52.6 \\
Age (years) & 99 & 51.0 \\
18 to 29 & 60 & 30.9 \\
30 to 39 & 35 & 18.1 \\
40 or older & & \\
Marital status & 81 & 41.8 \\
Married/ civil union & 94 & 48.4 \\
Single & 7 & 3.6 \\
Divorced/separated & 12 & 6.2 \\
Widowed & & 2.6 \\
Educational level (years) & 5 & 26.8 \\
0 to 4 & 52 & 45.9 \\
5 to 7 & 89 & 24.7 \\
8 to 11 & 48 & \\
12 or more & & \\
\hline
\end{tabular}


Table 1

Sample description and prevalence of emotional symptoms $(N=194)$

2 of 2

\begin{tabular}{|c|c|c|}
\hline Sociodemographic variables & $N$ & $\%$ \\
\hline \multicolumn{3}{|l|}{ Relation with the disaster } \\
\hline Indirect & 128 & 66.0 \\
\hline Direct & 66 & 34.0 \\
\hline Emotional symptoms & $N$ & $\%$ \\
\hline \multicolumn{3}{|l|}{ PTSD a symptoms } \\
\hline No & 141 & 72.6 \\
\hline Yes & 53 & 27.3 \\
\hline \multicolumn{3}{|l|}{ Depression symptoms } \\
\hline Normal & 90 & 46.3 \\
\hline Low & 31 & 15.9 \\
\hline Moderate & 38 & 19.5 \\
\hline Severe & 15 & 7.7 \\
\hline Extremely severe & 20 & 10.3 \\
\hline \multicolumn{3}{|l|}{ Anxiety symptoms } \\
\hline Normal & 92 & 47.4 \\
\hline Low & 27 & 13.9 \\
\hline Moderate & 30 & 15.4 \\
\hline Severe & 15 & 7.7 \\
\hline Extremely severe & 30 & 15.4 \\
\hline \multicolumn{3}{|l|}{ Stress symptoms } \\
\hline Normal & 103 & 53.0 \\
\hline Low & 23 & 11.8 \\
\hline Moderate & 30 & 15.4 \\
\hline Severe & 21 & 10.8 \\
\hline Extremely severe & 17 & 8.7 \\
\hline
\end{tabular}

Note: ${ }^{a}$ Post-traumatic stress disorder.

The results obtained by the bivariate analysis showed associations between the sociodemographic variables and the assessed symptoms (Table 2). It was observed that the highest prevalence of emotional symptoms related to post-traumatic stress disorder was found in women and a direct relationship with the disaster. Still, depression symptoms with severe and extremely severe signs showed associations with women, widowed, and directly involved individuals. As for anxiety and stress symptoms with severe and extremely severe signs revealed a high prevalence when individuals had been directly exposure to the crash.

Table 2

a Prevalence of emotional symptoms according to sociodemographic characteristics $(N=194)$

\begin{tabular}{|c|c|c|c|c|c|c|}
\hline \multirow{2}{*}{ Sociodemographic variables } & \multicolumn{3}{|c|}{ PTSD $^{a}$} & \multicolumn{3}{|c|}{ Depression $^{\mathbf{b}}$} \\
\hline & $\%$ & $p$ & Cramer's V & $\%$ & $p$ & Cramer's V \\
\hline Sex & & 0.021 & 0.1653 & & 0.036 & 0.1503 \\
\hline Men & 19.6 & & & 12.0 & & \\
\hline Women & 34.4 & & & 23.5 & & \\
\hline Age (years) & & 0.496 & 0.0850 & & 0.697 & 0.0611 \\
\hline 18 to 29 & 30.3 & & & 20.2 & & \\
\hline 30 to 39 & 26.7 & & & 16.7 & & \\
\hline 40 or older & 20.0 & & & 14.3 & & \\
\hline
\end{tabular}


Table 2

Prevalence of emotional symptoms according to sociodemographic characteristics ( $N=194)$

2 of 2

\begin{tabular}{|c|c|c|c|c|c|c|}
\hline \multirow{2}{*}{ Sociodemographic variables } & \multicolumn{3}{|c|}{ PTSD $^{a}$} & \multicolumn{3}{|c|}{ Depression $^{\mathbf{b}}$} \\
\hline & $\%$ & $p$ & Cramer's V & $\%$ & $p$ & Cramer's V \\
\hline Marital status & & 0.064 & 0.1936 & & 0.009 & 0.2437 \\
\hline Married/ civil union & 18.5 & & & 11.1 & & \\
\hline Single & 31.9 & & & 19.2 & & \\
\hline Divorced/separated & 28.6 & & & 28.6 & & \\
\hline Widowed & 50.0 & & & 50.0 & & \\
\hline Educational level (years) & & 0.162 & 0.1626 & & 0.414 & 0.1214 \\
\hline 0 to 4 & 20.0 & & & 20.0 & & \\
\hline 5 to 7 & 36.5 & & & 23.1 & & \\
\hline 8 to 11 & 28.1 & & & 19.1 & & \\
\hline 12 or more & 16.7 & & & 10.4 & & \\
\hline Relation with the disaster & & 0.001 & 0.2434 & & 0.001 & 0.3422 \\
\hline Indirect & 19.5 & & & 8.6 & & \\
\hline Direct & 42.4 & & & 36.4 & & \\
\hline \multirow{2}{*}{ Sociodemographic variables } & \multicolumn{3}{|c|}{ Anxiety } & \multicolumn{3}{|c|}{ Stress } \\
\hline & $\%$ & $p$ & Cramer's V & $\%$ & $p$ & Cramer's V \\
\hline Sex & & 0.1306 & & & 0.069 & 0.1306 \\
\hline Men & 17.4 & & & 14.1 & & \\
\hline Women & 28.4 & & & 24.5 & & \\
\hline Age (years) & & 0.368 & & & 0.671 & 0.0641 \\
\hline 18 to 29 & 24.2 & & & 21.2 & & \\
\hline 30 to 39 & 23.3 & & & 20.0 & & \\
\hline 40 or older & 20.0 & & & 14.3 & & \\
\hline Marital status & & 0.322 & 0.1342 & & 0.153 & 0.1648 \\
\hline Married/ civil union & 18.5 & & & 14.8 & & \\
\hline Single & 24.5 & & & 20.2 & & \\
\hline Divorced/separated & 28.6 & & & 28.6 & & \\
\hline Widowed & 41.7 & & & 41.7 & & \\
\hline Educational level (years) & & 0.179 & 0.1589 & & 0.550 & 0.1043 \\
\hline 0 to 4 & 20.0 & & & 20.0 & & \\
\hline 5 to 7 & 30.8 & & & 23.1 & & \\
\hline 8 to 11 & 24.7 & & & 21.4 & & \\
\hline 12 or more & 12.5 & & & 12.5 & & \\
\hline Relation with the disaster & & 0.041 & 0.1467 & & 0.001 & 0.2761 \\
\hline Indirect & 18.8 & & & 11.7 & & \\
\hline Direct & 31.8 & & & 34.9 & & \\
\hline
\end{tabular}

Note: $p>0.05$. 'Post-traumatic stress disorders; ${ }^{b}$ Severe and extremely severe symptoms. Pearson's chi-square test. Cramer's $V$ Test.

Multivariate logistic regression, controlling for possible confounding factors (sex, age, marital status, and educational level), was designed to identify the predictive value between sociodemographic variables with the emotional PTSD symptoms, depression, anxiety, and stress (Table 3). In this case, it was found that women, when compared to men, predicted the development of emotional PTSD symptoms (OR: $2.46 ; 95 \% \mathrm{Cl} 1.16-5.23, p=0.019)$. Direct victims, when compared to indirect victims, were more likely to manifest emotional PTSD symptoms (OR: 3.06; $95 \% \mathrm{Cl} 1.45-6.47, p=0.003$ ), depression (OR: $5.72 ; 95 \% \mathrm{Cl} 2.37-13.8, p=0.001)$ and stress (OR: $4.15 ; 95 \% \mathrm{Cl} 1.83-9.40, p=0.001)$ with severe and extremely severe signs. 
Table 3

Multivariate logistic regression for emotional symptoms according to sociodemographic characteristics $(N=194)$

\begin{tabular}{|c|c|c|c|c|}
\hline \multirow{2}{*}{ Sociodemographic variables } & \multicolumn{2}{|c|}{ PTSD $^{a}$} & \multicolumn{2}{|c|}{ Depression $^{\mathbf{b}}$} \\
\hline & OR (Cl95\%) & $p^{c}$ & OR (Cl95\%) & $p^{c}$ \\
\hline Age (years) & & 0.470 & & 0.645 \\
\hline 18 to 29 & 1 & & 1 & \\
\hline 30 to 39 & $1.42(0.58-3.49)$ & & $1.17(0.40-3.42)$ & \\
\hline 40 or older & $0.71(0.22-2.31)$ & & $0.59(0.14-2.49)$ & \\
\hline Sex & & 0.019 & & 0.086 \\
\hline Men & 1 & & 1 & \\
\hline Women & $2.46(1.16-5.23)$ & & $2.23(0.89-5.60)$ & \\
\hline Marital status & & 0.557 & & 0.674 \\
\hline Married/civil union & 1 & & 1 & \\
\hline Single & $1.84(0.79-4.30)$ & & $1.46(0.52-4.16)$ & \\
\hline Divorced/separated & $1.50(0.23-10.1)$ & & $3.00(0.39-23.2)$ & \\
\hline Widowed & $1.24(0.29-5.36)$ & & $1.64(0.35-7.72)$ & \\
\hline Educational level (years) & & 0.112 & & 0.386 \\
\hline 0 to 4 & 1 & & 1 & \\
\hline 5 to 7 & $2.29(0.20-26.6)$ & & $1.39(0.10-19.5)$ & \\
\hline 8 to 11 & $1.32(0.12-14.8)$ & & $0.97(0.07-12.9)$ & \\
\hline 12 or more & $0.63(0.05-8.04)$ & & $0.45(0.03-7.23)$ & \\
\hline Relation with the accident & & 0.003 & & 0.001 \\
\hline Indirect & 1 & & 1 & \\
\hline Direct & $3.06(1.45-6.47)$ & & $5.72(2.37-13.8)$ & \\
\hline \multirow{2}{*}{ Sociodemographic variables } & \multicolumn{2}{|c|}{ Anxiety $^{\mathbf{b}}$} & \multicolumn{2}{|c|}{ Stress $^{\mathbf{b}}$} \\
\hline & OR (C195\%) & $p^{c}$ & OR (C195\%) & $p^{c}$ \\
\hline Age (years) & & 0.684 & & 0.698 \\
\hline 18 to 29 & 1 & & 1 & \\
\hline 30 to 39 & $1.40(0.56-3.47)$ & & $1.30(0.48-3.49)$ & \\
\hline 40 or older & $0.92(0.28-2.97)$ & & $0.53(0.14-2.07)$ & \\
\hline Sex & & 0.056 & & 0.088 \\
\hline Men & 1 & & 1 & \\
\hline Women & $2.10(0.98-4.51)$ & & $2.09(0.90-4.87)$ & \\
\hline Marital status & & 0.928 & & 0.440 \\
\hline Married / civil union & 1 & & 1 & \\
\hline Single & $1.29(0.55-3.06)$ & & $1.13(0.44-2.92)$ & \\
\hline Divorced/separated & $1.43(0.22-9.31)$ & & $2.44(0.35-16.9)$ & \\
\hline Widowed & $1.30(0.29-5.73)$ & & $0.94(0.21-4.27)$ & \\
\hline Educational level (years) & & 0.138 & & 0.523 \\
\hline 0 to 4 & 1 & & 1 & \\
\hline 5 to 7 & $1.72(0.16-18.6)$ & & $1.20(0.10-14.4)$ & \\
\hline 8 to 11 & $1.16(0.11-12.0)$ & & $1.02(0.09-11.6)$ & \\
\hline 12 or more & $0.46(0.04-5.57)$ & & $0.49(0.03-6.50)$ & \\
\hline Relation with the accident & & 0.111 & & 0.001 \\
\hline Indirect & 1 & & 1 & \\
\hline Direct & $1.87(0.87-4.02)$ & & $4.15(1.83-9.40)$ & \\
\hline
\end{tabular}

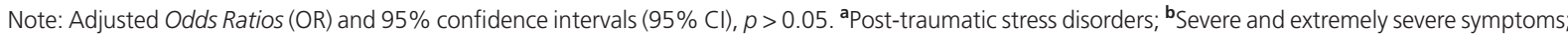
'Adjusted for the age, sex, marital status, educational level, and relation with the accident variables.

\section{Discussion}

From the results obtained it was possible to identify that the emotional symptoms related to post-traumatic stress disorder, depression and stress are influenced by the sex and direct relationship with 8 the tragedy sociodemographic variables. Regarding the sociodemographic profile of the participants, it was 
found that most participants were women, with incomplete and complete higher education, and single. Considering the degree of involvement with the tragedy, a large part of the sample represents indirect victims (Preto et al., 2018). In general, the analyzes indicated that a considerable portion of the participants did not have a significant prevalence of PTSD, depression, anxiety, and stress symptoms.

On the other hand, Bonanno et al. (2010) showed that, although many subjects return to their level of functioning prior to the disaster, there is a subset of the population that continues to present psychological problems. In this sense, it can be assumed that, even after two years of the disaster, some people may still be emotionally impacted, since a significant number of $27.3 \%$ of respondents indicated characteristics that are compatible with post-traumatic stress disorder (OPAS, 2018).

Consistent with what had been predicted, PTSD scores were significantly higher and are in line with previous studies (Farooqui et al., 2017; North, 2016). Then, the highest prevalences observed were found in anxiety symptoms, where $7.7 \%$ of the subjects manifested severe and $15.4 \%$ extremely severe intensities. Subsequently, the highest scores were obtained in stress levels, with $10.8 \%$ showing severe and $8.7 \%$ extremely severe intensities. Finally, it was observed that depression symptoms had levels of $7.7 \%$ in severe and $10.3 \%$ for extremely severe intensities, numbers corroborated by the literature (Reis \& Carvalho, 2016).

However, as already portrayed by Bonanno et al. (2010), the proportion of symptoms and mental illnesses in any sample will vary according to the degree of exposure to trauma and the sociodemographic characteristics. In view of this, this study proposed to identify the prediction of sociodemographic characteristics on emotional symptoms in a sample of people who experienced an air disaster. Regarding the influence of individual variables, the results show that, as expected, the emotional PTSD, depression, and stress symptoms were influenced by these factors.

In this study, as in others with a similar design, women were associated with the outcomes, even if adjusted for several confounding factors (León-Amenero \& Huarcaya-Victoria, 2019). Regarding the emotional symptoms assessed, it was found that women showed an increase of 2.46 in the odds ratios of manifesting signs corresponding to post-traumatic stress disorder. Differences between women and men were found in prospective studies to determine the incidence of mental disorders (Laugharne et al., 2011).

It can be seen from the existing data that women have a higher prevalence of PTSD and that these symptoms have a longer duration among women. According to a study by Pulcino et al. (2003) after the terrorist attacks on the World Trade Center, they found that the prevalence of PTSD was 9.9\% for women and only $4.8 \%$ for men.

Some hypotheses are mentioned in the literature to clarify these results. Firstly, there is consensus among the authors that the disparities in the prevalence of PTSD between men and women are constituted by the plurality of biological, social, and psychological factors involved. Considering these aspects, above all, the relationship between the ways of socializing and the expectations of the social roles of each sex is highlighted to society. It is observed that, still, men have attributed a more rational, independent, controlling, and aggressive posture. Furthermore, they show more difficulties in expressing their problems and feelings, as this is socially interpreted as a sign of weakness (Borba et al., 2017).

On the other hand, studies show that women have an easier time communicating their emotions and adversities, tend to show more empathy with the feelings of others, as well as demonstrate a greater investment and dependence on interpersonal relationships, when compared with men. Additionally, it must be considered that, in recent decades, social changes have caused women to be asked to financially contribute to support the family, to get a job to generate income and, at the same time, to remain responsible for domestic duties that were already theirs. This exercise of multiple roles can cause an overload of work and responsibility, also contributing to the manifestation of psychic symptoms (Borba et al., 2017; Pulcino et al., 2003). 
In addition, it was verified through the data obtained that the widowed marital status only showed an association with depression symptoms, in the bivariate analysis. Nevertheless, the sociodemographic factor (widowed, divorced, or single) did not predict the onset of emotional symptoms assessed in the multivariate analysis, diverging from other studies that found significant associations between these variables (Hibberd et al., 2014). The explanation is that marital status (married or in a stable relationship) can be considered a form of social support, as it offers people emotional support and instrumental help with day-to-day tasks (Bonanno et al., 2010).

The age variable, on the other hand, did not reveal associations with the assessed symptoms. These results contrast the evidence from other studies, in which younger and older people had a higher prevalence of PTSD and depression symptoms (Arnberg et al., 2015). The assumption is that younger people show more emotional and financial dependence on adults, in addition to having less life experience, since it is possible to assume a cumulative effect of exposure to stressors on mental health (North et al., 2015). Likewise, older adults may be more prone to emotional impacts, due to age-specific needs and vulnerabilities, just as the degree of dependence tends to be greater at this stage in life (Bonanno et al., 2010).

Therefore, the absence of associations between educational level and outcomes was another unexpected result, since lower educational levels have been described in the literature as a factor associated with the emotional symptoms assessed (Quadros et al., 2020). This could be partially explained by the positive effect of educational level on mental health, which affects self-esteem, access to quality information on health, and a greater for services and health professionals, which helps in quality of life (Arnberg et al., 2015). However, it was not the result found in this study.

The lack of associations between variables - marital status, age, and educational level - with PTSD symptoms, such as depression, anxiety, and stress, leads us to think that, probably, new approaches are necessary to complement the understanding of sociodemographic factors, as these aspects affect mental health. In addition, it is necessary to consider that these results may have been influenced by the fact that most of the participants experienced the disaster in an indirect manner and, according to the study clarifications, these people have lower levels of symptoms and mental illnesses, when compared to the most exposed individuals (Catanesi et al., 2013). Furthermore, the time (two years) elapsed between the tragedy and data collection may also have affected this outcome.

With regard to the direct victim variable, it was revealed that these people show a higher prevalence of emotional PTSD and stress symptoms, especially a significant increase of 5.27 in the odds ratios to trigger depression symptoms with severe and extremely severe signs. These results are consistent with data reported in the literature. Previous studies have found that direct victims of a disaster were more likely to manifest psychological problems than indirect victims, regardless of national or political consequences caused by a disaster (Steffens, 2018). A similarly designed study by Laugharne et al. (2011) found that the people most involved in the World Trade Center terrorist attacks demonstrated significant associations with depressive symptoms, showing scores of $16.1 \%$ in people who were directly exposed and $4.4 \%$ for individuals who were indirectly exposed.

There are controversies in the literature about the course of PTSD and depression. Some studies show a delay in the onset of symptoms (North, 2016) others indicate that the symptoms decrease with time in the general population, however they tend to persist among the most exposed subjects (Arnberg et al., 2015). This same trend was observed in this study, in which many direct victims still show emotional symptoms, even two years after the tragedy. However, it cannot be inferred whether the cause of these manifestations are the effects of the disaster.

In view of these findings, some hypotheses can be suggested to assist in the understanding of these outcomes. Initially, Kristensen et al. (2014) point out that sudden events, such as disasters, present a more 
complex and slow recovery trajectory. This is because the suddenness of the situation prevents bereaved relatives from saying goodbye one last time to their beloved one. Accordingly, some studies point out that, generally, in intentional man-made disasters, there is someone to blame for the cause of the tragedy (North, 2016).

Another aspect to be considered refers to the contribution of the media and the internet, which, through incessant coverage, hinder the process of coping by victims (van Der Velden et al., 2018). After the announcement of the disaster and until today, it is noted that the media continue to broadcast information about the tragedy, through news, films, and documentaries. Ahern et al. (2002) stress that this coverage is negative, as it acts as a constant reminder. In her research the author identified that the directly exposed participants who followed the news, showed three times more chances to trigger PTSD and depression.

In general, the data obtained showed a strong relationship between the outcomes and the individual factors, such as female sex and direct relationship with the tragedy. Personal characteristics need to be considered in intervention programs with populations affected by disasters, in order to rethink professional reintegration and the management of emotions, minimizing the triggering of PTSD, depression, anxiety, and stress symptoms, among other psychopathologies.

\section{Conclusion}

The results found in this study indicate that only exposure to a disaster is not a determining condition for these outcomes, since the individual variables are important moderators for the triggering of the emotional symptoms assessed. The results showed that the sociodemographic variables - women and direct exposure had higher odds ratios to trigger emotional PTSD, depression, and stress symptoms with severe and extremely severe signs. Still, it was observed that the victims directly involved had a higher prevalence of PTSD symptoms.

In such a way, it is emphasized that the proposed objectives were contemplated. Thus, this research aims to contribute to the advancement of scientific knowledge, considering that Brazilian research on the subject is still scarce. This data is expected to reveal the people who may be most vulnerable to the triggering of psychic symptoms. Furthermore, it aims to provide information to people who experience similar situations and to contribute to the elaboration and improvement of effective interventions, with populations that experience similar situations.

However, these results must be interpreted considering the limitations inherent in cross-sectional studies, thus making it impossible to generalize the results. Another limitation refers to the selected instruments, as they are self-applied, there may be inaccuracies in the understanding of the questions and consequently in the answers. In such a way, it is important that future investigations understand the exposure of the studied variables and others that, in this study, were not selected - such as the use of medication, psychotherapy, religious practices, and others that may influence the outcomes of the outcomes. Therefore, further studies on the phenomenon are suggested, including investigations with longitudinal designs and larger samples, with the purpose of understanding the associations between sociodemographic variables, symptoms and psychopathological disorders, among other clarifications.

\section{Contributors}

G. LENHARDT participated in the general conception of research, design, analysis and interpretation of data, and general review. I. ANDRETTA was responsible for the conception and design of the study, review, and approval of the final version of the article. 


\section{References}

Ahern, J., Galea, S., Resnick, H., Kilpatrick, D., Bucuvalas, J. M., Gold, J., \& Vlahov, D. (2002). Television images and psychological symptoms after the September 11 terrorist attacks. Psychiatry, 65(4), 289-300. http://dx.doi.org/10.1521/ psyc.65.4.289.20240

American Psychiatric Association. (2014). DSM-5: manual diagnóstico e estatístico de transtornos mentais. Porto Alegre: Artmed, 2014.

Apóstolo, J. L. A., Mendes, A. C., \& Azeredo, Z. A. (2006). Adaptação para a língua portuguesa da Depression, Anxiety and Stress Scale (DASS). Revista Latino-Americana de Enfermagem, 14(6), 863-871. http://dx.doi.org/10.1590/S010411692006000600006

Arnberg, F. K., Michel, P. O., \& Lundin, T. (2015). Posttraumatic stress in survivors 1 month to 19 years after an airliner emergency landing. Plos One, 10(3), e0119732. http://dx.doi.org/10.1371/journal.pone.0119732

Barlow, D. H. (2016). Manual clínico dos transtornos psicológicos: tratamento passo a passo. Porto Alegre: Artmed.

Berger, W., Mendlowicz, M. V., Souza, W. F., \& Figueira, I. (2004). Equivalência semântica da versão em português da Post-Traumatic Stress Disorder Checklist - Civilian Version (PCL-C) para rastreamento do transtorno de estresse pós-traumático. Revista de Psiquiatria do Rio Grande do Sul, 26, 167-175. http://dx.doi.org/10.1590/S010181082004000200006

Bonanno, G. A., Brewin, C. R., Kaniasty, K., \& Greca, A. M. L. (2010). Weighing the costs of disaster: consequences, risks, and resilience in individuals, families, and communities. Psychological Science in the Public Interest, 11(1), 1-49. http://dx.doi.org/10.1177/1529100610387086

Borba, L. O., Maftum, M. A., Vayego, S. A., Kalinke, L. P., Ferreira, A. C. Z., \& Capistrano, F. C. (2017). The mental disorder profile of patients treated at CAPS. Revista Mineira Enfermagem, 21, e1010, 1-7. http://www.dx.doi. org/10.5935/1415-2762.20170020

Catanesi, R., Martino, V., Candelli, C., Troccoli, G., Grattagliano, I., Vella, G. D., \& Carabellese, F. (2013). Posttraumatic stress disorder: protective and risk factors in 18 survivors of a plane crash. Journal of Forensic Sciences, 58(5), 13881392. http://dx.doi.org/10.1111/1556-4029.12178

Cénat, J. M., \& Derivois, D. (2014). Assessment of prevalence and determinants of posttraumatic stress disorder and depression symptoms in adults survivors of earthquake in Haiti after 30 months. Journal of Affective Disorders, 159, 111-117. http://dx.doi.org/10.1016/j.jad.2014.02.025

Chung, M. C., Easthope, Y., Chung, C., \& Clark-Carter, D. (2001). Traumatic stress and coping strategies of sesternary victims following an aircraft disaster in Coventry. Stress and Health, 17(2), 67-75. http://dx.doi.org/10.1002/smi.881

Emygdio, N. B., Fuso, S. F., Mozzambani, A. C. F., Acedo, N. A., Rodrigues, C. C., \& Mello, M. F. (2019). Efeitos do transtorno de estresse pós-traumático na memória. Psicologia: Ciência e Profissão, 39, e174817. http://dx.doi. org/10.1590/1982-3703003174817

Farooqui, M., Quadri, S. A., Suriya, S. S., Khan, M. A., Ovais, M., Sohail, Z., ... Hassan, M. (2017). Posttraumatic stress disorder: a serious post-earthquake complication. Trends in Psychiatry and Psychotherapy, 39(2), 135-143. http:// dx.doi.org/10.1590/2237-6089-2016-0029

Hiany, N., Vieira, M. A., Gusmão, R. O., \& Barbosa, S. (2020). perfil epidemiológico dos transtornos mentais na população adulta no Brasil: uma revisão integrativa. Revista Enfermagem Atual in Derme, 86(24), 1-11. https://doi.org/10.31011/ reaid-2018-v.86-n.24-art.676

Hibberd, R., Elwood, L., \& Galovski, T. (2014). Risk and protective factors for posttraumatic stress disorder, prolonged grief, and depression in survivors of the violent death of a loved one. Journal of Loss and Trauma, 15(5), 426-447. http://dx.doi.org/10.1080/15325024.2010.507660

Kristensen, P., Weisæth, L., \& Heir, T. (2014). Bereavement and mental health after sudden and violent losses: a review. Psychiatry: Interpersonal and Biological Processes, 75(1), 76-97. http://dx.doi.org/10.1521/psyc.2012.75.1.76

Laugharne, J., van der Watt, G., \& Janca, A. (2011). After the fire: the mental health consequences of fire disasters. Current Opinion in Psychiatry, 24(1), 72-77. http://dx.doi.org/10.1097/YCO.0b013e32833f5e4e

León-Amenero, D., \& Huarcaya-Victoria, J. (2019). Salud mental en situaciones de desastres. Horizonte Médico, 19(1), 73-80. http://dx.doi.org/10.24265/horizmed.2019.v19n1.12

Lovibond, P. F., \& Lovibond, S. H. (1995). The structure of negative emotional states: comparison of the Depression Anxiety Stress Scales (DASS) with the Beck depression and anxiety inventories. Behaviour Research and Therapy, 33(3), 335-343. http://dx.doi.org/10.1016/j.rbp.2012.05.003 
Mao, X., Fung, O. W. M., Hu, X., \& Loke, A. Y. (2018). Psychological impacts of disaster on rescue workers: a review of the literature. International Journal of Disaster Risk Reduction, 27, 602-617. http://dx.doi.org/10.1016/j.ijdrr.2017.10.020

North, C. S. (2016). Disaster mental health epidemiology: methodological review and interpretation of research findings. Psychiatry, 79(2), 130-146. http://dx.doi.org/10.1080/00332747.2016.1155926

North, C. S., Pollio, D. E., Hong, B. A., Pandya, A., Smith, R. P., \& Pfefferbaum, B. (2015). The post disaster prevalence of major depression relative to PTSD in survivors of the 9/11 attacks on the world trade center selected from affected workplaces. Comprehensive Psychiatry, 60, 119-125. http://dx.doi.org/10.1016/j.comppsych.2015.02.009

Organização Pan-Americana da Saúde. (2018). Folha informativa Depressão. Brasília: Autor. Recuperado de https://www. paho.org/bra/index.php?option=com_content\&view=article \&id=5635:folha-informativa-depressao\&ltemid=1095

Preto, V. A, Benevides, M. S, Queiroz, B. G, Pereira, S. S., Souza, B. O. P, Sailler, G. C., \& Cardoso L. (2018). Stress and sociodemographic characteristics of undergraduate nursing students. Journal of Nursing, 12(3), 701-707. https://doi. org/10.5205/1981-8963-v12i3a231060p701-707-2018

Pulcino, T., Galea, S., Ahern, J., Resnick, H., Foley, M., \& Vlahov, D. (2003). Posttraumatic stress in women after the September 11 terrorist attacts in New York City. Journal of Women's Health, 12(8), 809-820. http://dx.doi. org/10.1089/154099903322447774

Quadros, L. C. M., Quevedo, L. A., Gonçalves, H. D., Horta, B. L., Motta, J. V. S., \& Gigante, D. P. (2020). Common mental disorders and contemporary factors: 1982 Birth Cohort. Revista Brasileira de Enfermagem, 73(1), 1-7. http:// dx.doi.org/10.1590/0034-7167-2018-0162

Reis, A. M., \& Carvalho, L. F. (2016). Scientific literature about Post-Traumatic Stress Disorder in disaster context. Avaliação Psicológica, 15(2), 237-247. http://dx.doi.org/10.15689/ap.2016.1502.12

Sampieri, R. H., Collado, C. F., \& Lucio, M. P. (2013). Metodologia de Pesquisa. Porto Alegre: Artmed.

Santos, G. B. V., Alves, M. C. G. P., Goldbaum M., Cesar C. L. G., \& Gianini R. J. (2019) Prevalência de transtornos mentais comuns e fatores associados em moradores da área urbana de São Paulo, Brasil. Cadernos de Saúde Pública, 35(11), 1-10. https://doi.org/10.1590/0102-311x00236318

Steffens, S. R. (2018). Desastres naturais: aspectos psicológicos e transtornos de estresse pós-traumático oriundos de uma inundação. Anuário Pesquisa e Extensão, 3, e19667. Recuperado de https://portalperiodicos.unoesc.edu.br/ apeusmo/article/view/19667/10438

Tsujiuchi, T., Yamaguchi, M., Masuda, K., Tsuchida, M., Inomata, T., Kumano, H., ... Mollica, F. A. (2016). High prevalence of post-traumatic stress symptoms in relation to social factors in affected population one year after the fukushima nuclear disaster. Plos One, 11(3), e0151807. http://dx.doi.org/10.1371/journal.pone.0151807

van Der Velden, P. G., van Der Meulen, E., Lenferink, L. I. M., \& Yzermans, J. C. (2018). Media experiences and associations with mental health among the bereaved of the MH17 disaster: a latent profile analysis. Scandinavian Journal of Psychology, 59(3), 281-288. http://dx.doi.org/10.1111/sjop.12426

Walton, J. L., Cuccurullo, L. A., Raines, A. M., Vidaurri, D. N., Allan, N. P., Maieritsch, K. P., \& Franklin, C. L. (2017). Sometimes less is more: establishing the core symptoms of PTSD. Journal of Traumatic Stress, 30(3), 254-258. http:// dx.doi.org/10.1002/jts.22185

Weathers, F. W., Litz, B. T., Herman, D., Huska, J. A., \& Keane, T. M. (1993). The PTSD Checklist (PCL): reliability, validity, and diagnostic utility. Proceedings of the Annual Meeting of International. Society for Traumatic Stress Studies, San Antonio.

Received: November 1, 2019

Final version: September 1, 2020

Approved: September 21, 2020 